\title{
THE VALUE OF THE MARCHI METHOD FOR STAINING TISSUE STORED IN FORMALIN FOR PROLONGED PERIODS
}

\author{
BY \\ MARION C. SMITH, SABINA J. STRICH,* and PETER SHARP \\ From the National Hospital for Nervous Diseases, Queen Square, London, and the Radcliffe Infirmary, Oxford
}

This paper reports the demonstration of degenerating myelin by the Marchi method in material kept in formalin for periods ranging from 22 months to over eight years.

It has generally been believed that prolonged immersion in formalin renders material useless for investigation by the Marchi method, because of the constant occurrence of extensive artefacts. Fourteen days has usually been considered the maximum period during which tissue may be exposed to the action of formalin before making Marchi preparations in order to obtain clear incontrovertible evidence of myelin degeneration. In Marchi preparations the presence of abundant black pseudoMarchi bodies, or of black staining of normal myelin sheaths, may completely obscure the tissue degeneration.

Bertrand wrote in 1930 :

" Sur toutes les préparations au Marchi existe une fine poussière de granulations noirâtres sans rapport avec un processus dégénératif quelconque, il nous a semblé que cet aspect était particulièrement marqué après une longue fixation au formol, sur un matériel ancien. Il est même fréquent de voir des gâines de myéline normale noircies sur un segment plus ou moins éxtendu de leur circonférence."

Swank and Davenport (1934) stated : "Prolonged formalin fixation .... increased the dust." They also showed that prolonged fixation (for one year) causes staining of the normal myelin sheaths. They considered the artefacts caused by formalin fixation to be the result of prolonged action of that fixative on the lipoids. Later, in 1942, Mettler and Hanada wrote : " The brain should never be allowed to fix in formalin alone for more than 24 hours." These are only examples of numerous similar statements. Occasional reference has been made to satisfactory Marchi preparations obtained after rather longer storage in formalin than usual. Poirier, Ayotte, and Gauthier (1954), in a paper describing a modified form of the Marchi method, showed a photograph of clear degeneration in a monkey after 100 days in formalin. But no worker, to our knowledge, has

\footnotetext{
* In receipt of a personal grant from the Medical Research Council.
}

given conclusive evidence that material stored for many months in formalin is still suitable for examination by the Marchi method.

We report here our results with the Marchi method in four cases of head injury. In these patients the interval between injury and death varied between nine and 15 months. The material from these cases had been stored in formol-saline for periods ranging from 22 to 100 months before examination. The period of survival after the lesion, and the period of storage in formol-saline in each case are shown in the Table.

TABLE

PERIODS OF SURVIVAL AND FIXATION

\begin{tabular}{c|c|c}
\hline Case & $\begin{array}{c}\text { Period of Survival } \\
\text { after Lesion } \\
\text { (months) }\end{array}$ & $\begin{array}{c}\text { Period of Formalin } \\
\text { Fixation } \\
\text { (months) }\end{array}$ \\
\hline A & 9 & 22 \\
B & 11 & 26 \\
D & 15 & 43 \\
\hline
\end{tabular}

The method employed in staining this old material was essentially that recommended by Swank and Davenport (1934) and modified by Glees (1943). But it was found advantageous to mount some frozen sections without dehydration or clearing, as well as sections which were dehydrated and cleared in the usual manner before mounting. After impregnating the blocks with the osmic acid solution for 10 days, they were washed in running water for 24 to 48 hours; the length of the washing time depended on the size of the blocks.

Frozen sections were cut $24 \mu$ thick and put into distilled water. The sections were either mounted directly in glycerine jelly without clearing, or dehydrated, cleared in cedar wood oil, and mounted in balsam. Some blocks were embedded in celloidin.

In the frozen sections it was noted that blackstained degenerating material showed up far more distinctly in the uncleared preparations than in those which were cleared. This was due partly to the tendency of some of the Marchi material to dissolve out into the clearing reagents and partly to the extreme paleness of the background. For topographical purposes the uncleared preparations 

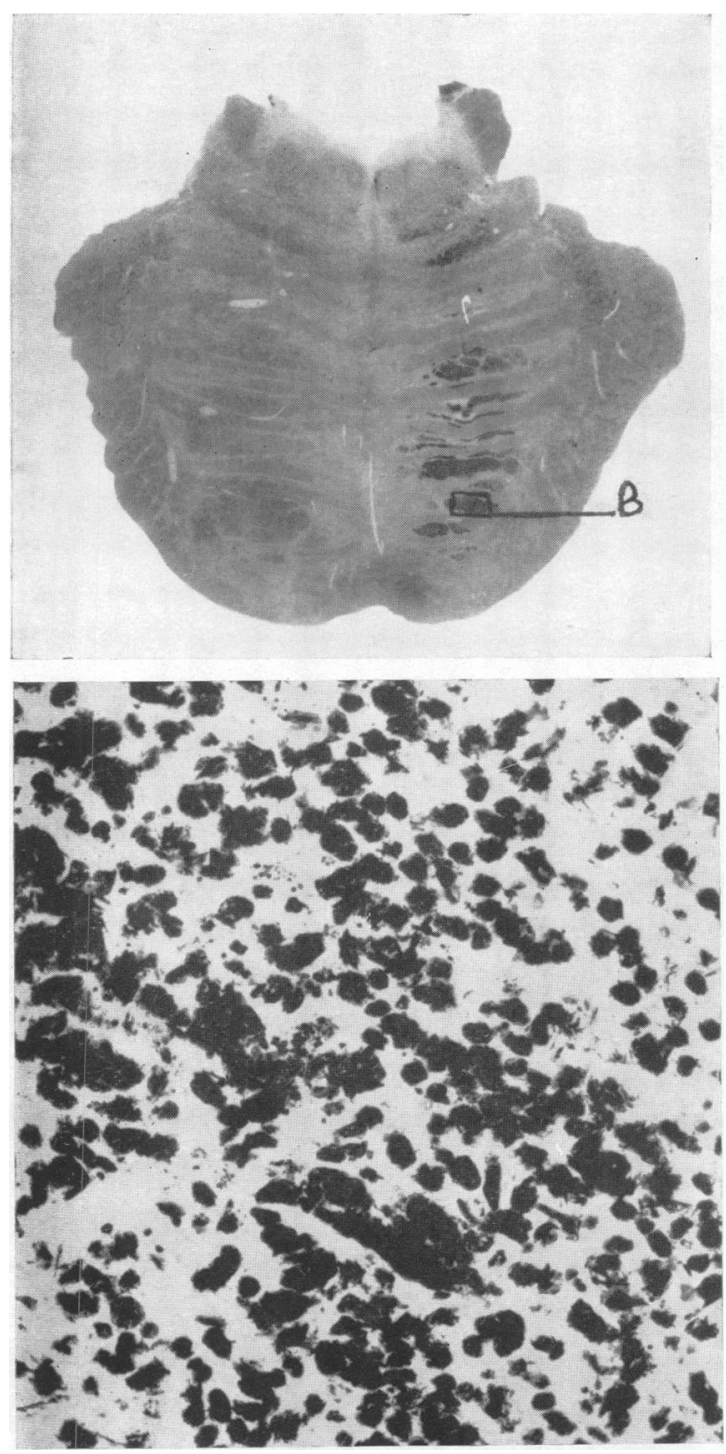

Fig. 1.-A and B.-Case A. Period of survival : nine months. Period of formalin fixation : 22 months.

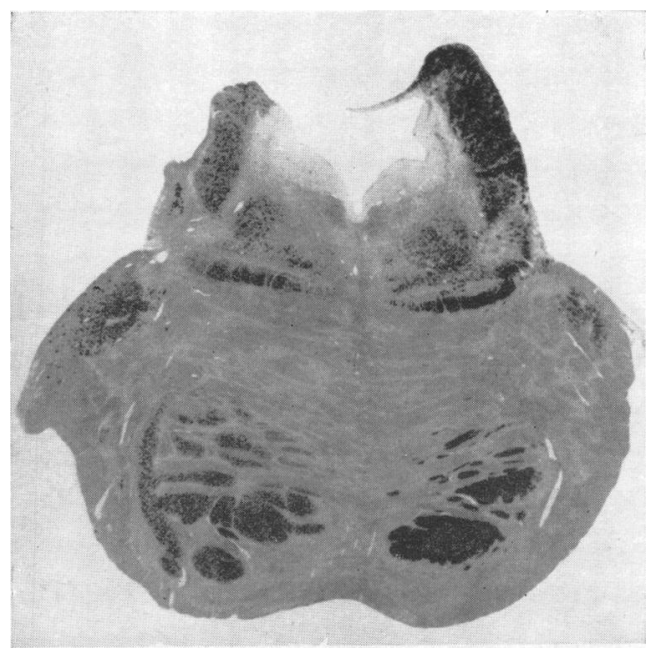

Fig. 3.-Case C. Period of survival : 15 months. Period of formalin fixation : 43 months.



FIG. 4.-Case D. Period of survival : 12 months. Period of formalin fixation : 100 months.

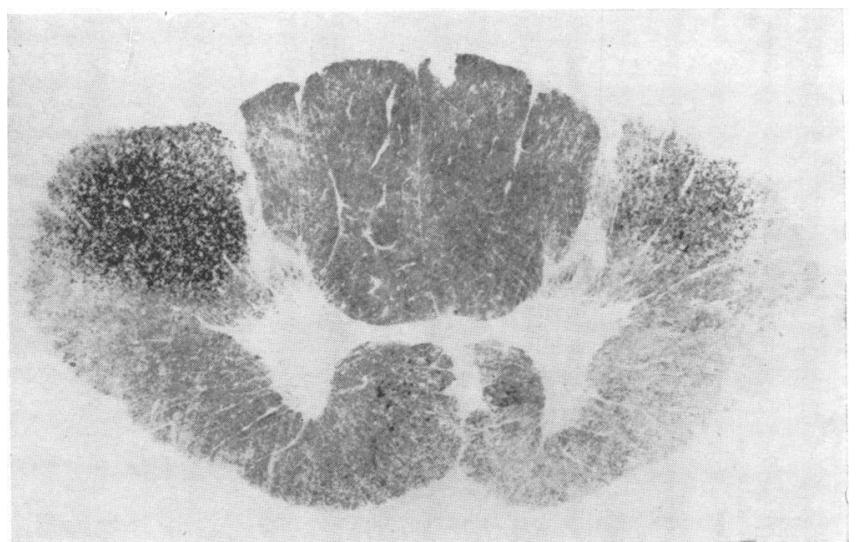

FIG. 2.-Case B. Period of survival : 11 months. Period of formalin fixation : 26 months.

In all cases the photographs are from uncleared preparations. The products of degenerating myelin are stained black in every case. 
were found to be completely satisfactory. When first mounted the background in these uncleared preparations was pale, in the course of the following four weeks the background darkened, and the preparations were then found to be more suitable for photography. Photographs of frozen, uncleared preparations from each of the cases are shown in Figs. 1 to 4 . In no case were there any artefacts or non-penetration of the blocks. In the celloidin sections, the normal myelin became brown after the sections were in alcohol. There was, therefore, a more clearly defined background to the blackstained degenerating myelin. But as some of the black Marchi-stained material dissolved out during the process of dehydration and embedding, a less dramatic picture was obtained in celloidin than in the uncleared frozen sections.

In all four cases the Marchi-stained material was mostly contained in compound granular corpuscles. The distribution of these cells was in keeping with the distribution of demyelinated areas in sections from adjacent blocks of tissue stained to demonstrate the myelin, although the picture of myelin damage was much more striking in the Marchi preparations.

It has therefore been shown that the Marchi method is of value in demonstrating degeneration, even after prolonged storage of the tissue in formolsaline.
In work on human neuro-anatomy, comparatively little material becomes available in which conditions for tracing degenerating fibres are optimum, and frequently material has been long in formol-saline before there is an opportunity for examining it histologically. As the Marchi method allows of the demonstration of even a few degenerating fibres by staining these fibres themselves, it is of great use in determining the course of tracts or in proving the presence of fibre degeneration. It is therefore hoped that our observation that the method is applicable to long-stored material may prove of value to other workers.

\section{Summary}

Clear, positive Marchi staining is reported in four cases of head injury occurring nine to 15 months before death. Formalin fixation in these cases had been continued from nearly two years to over eight years before the material was examined by the Marchi method.

\section{REFERENCES}

Bertrand, I. (1930). Techniques Histologiques de Neuropathologie. Masson, Paris.

Glees, P. (1943). Brain, 66, 229.

Mettler, F. A., and Hanada, R. E. (1942). Stain Tech., 17, 111.

Poirier, L. J., Ayotte, R. A., and Gauthier, C. (1954)., Ibid., 29, 71. Swank, R. L., and Davenport, H. A. (1934). Ibid., 9, 129. 